This item was submitted to Loughborough's Research Repository by the author.

Items in Figshare are protected by copyright, with all rights reserved, unless otherwise indicated.

\title{
Colloidal fouling of microfiltration membranes during the treatment of aqueous feed streams
}

PLEASE CITE THE PUBLISHED VERSION

PUBLISHER

(C) Elsevier

VERSION

AM (Accepted Manuscript)

LICENCE

CC BY-NC-ND 4.0

\section{REPOSITORY RECORD}

Wakeman, Richard J., and E.S. Tarleton. 2009. "Colloidal Fouling of Microfiltration Membranes During the Treatment of Aqueous Feed Streams”. figshare. https://hdl.handle.net/2134/5128. 
This item was submitted to Loughborough's Institutional Repository (https://dspace.lboro.ac.uk/) by the author and is made available under the following Creative Commons Licence conditions.

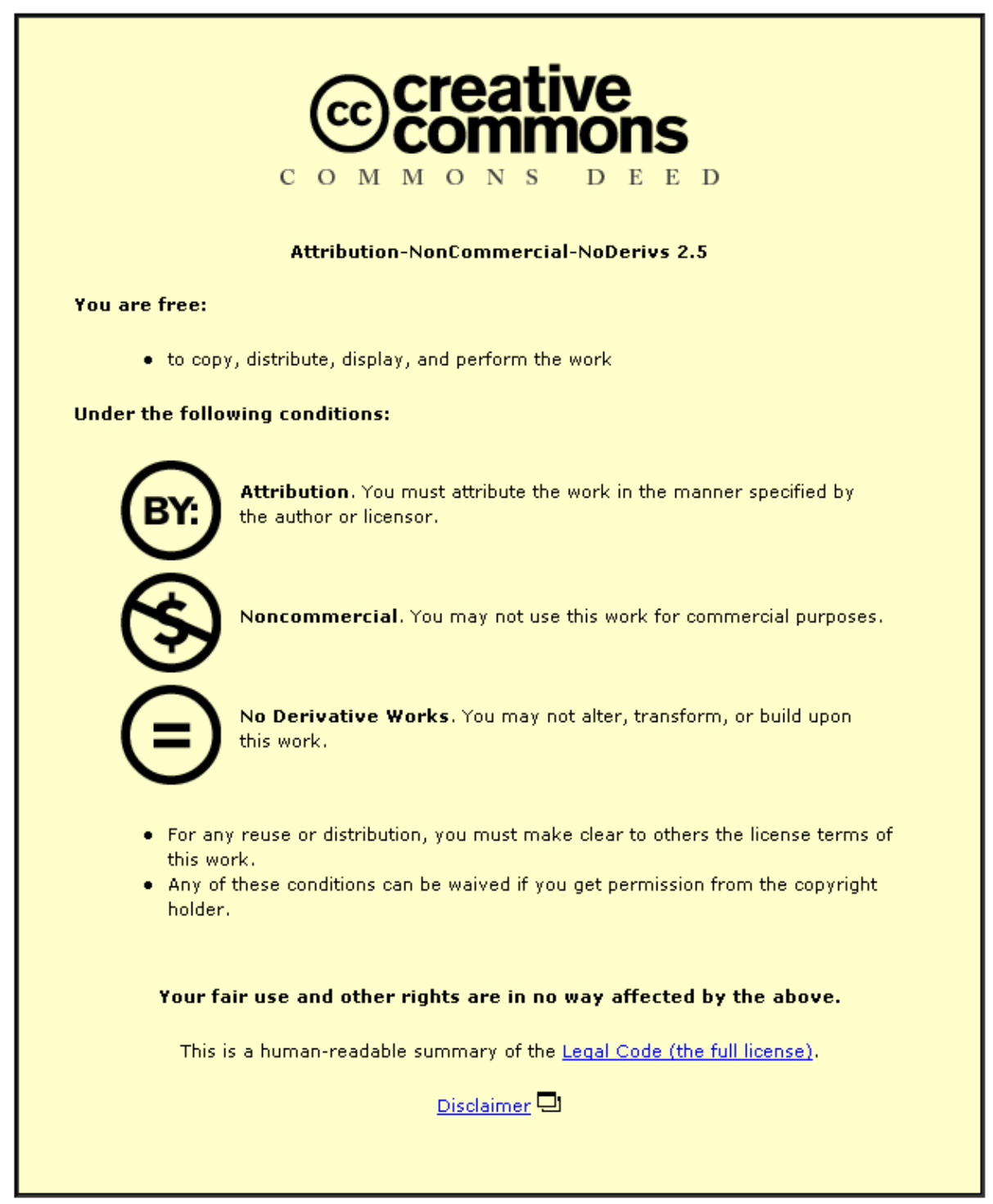

For the full text of this licence, please go to: http://creativecommons.org/licenses/by-nc-nd/2.5/ 


\title{
COLLOIDAL FOULING OF MICROFILTRATION MEMBRANES DURING THE TREATMENT OF AQUEOUS FEED STREAMS
}

\author{
R.J. Wakeman and E.S. Tarleton (e.s.tarleton@lboro.ac.uk) \\ Separation Processes Centre, University of Exeter, Exeter, UK.
}

\begin{abstract}
Experimental data has been obtained from a computer controlled crossflow microfiltration apparatus. Polymer membranes of differing properties have been used to filter suspensions carrying colloidal and fine particles of known shape, size, surface charge and chemical composition. The process parameters (feed concentration, crossflow velocity and pressure difference) have been changed systematically, and flux decline curves measured for the matrix of particle, suspension, and process properties. This paper presents results from the experimental programme, and in the light of these results explains some of the apparent anomalies which have been presented in previous publications.
\end{abstract}

\section{INTRODUCTION}

Permeate flux decline curves observed in crossflow microfilters have been measured and reported by most workers who have involved themselves in microfiltration and ultrafiltration. The work relating to microfiltration has not generally taken due account of all the relevant variables and has often used feed streams containing mixtures of molecules and particulates, either or both of which may be membrane foulants either in combination or in their own right. A full understanding of membrane fouling cannot be obtained unless all the variables are properly delineated, and separated out in an appropriately designed experimental programme using a well controlled filtration apparatus. The work presented in this paper represents an initial step in this direction, focussing on the fouling propensity of colloidal and fine particulate matter.

\section{EXPERIMENTAL TECHNIQUES AND PROCEDURES}

The experimental programme can be conveniently divided into two parts: characterisation tests to provide background knowledge and the properties of the particles, suspensions, membranes, and the interfacial properties between them, and filtration fouling experiments.

\section{Membrane Fouling Assessment Experiments}

The equipment used to assess membrane fouling behaviour is shown schematically in Figure 1. The unit comprised a flow circuit in which suspension of a known, essentially constant, composition was pumped continuously through a crossflow microfilter at a predefined crossflow velocity and trans-membrane pressure. These desired filtration conditions were maintained by two electrically operated proportional control valves. The valves were linked to a computer via electronic control circuitry which monitored conditions at various points within the flow circuit using suitable transducers. When a deviation from the desired conditions was detected the control valves moved to compensate and thus maintain a constant filtration pressure and crossflow velocity. The temperature of the process suspension was also regulated using a plate type heat exchanger positioned in the feed tank. In this way it was possible to vary the filtration pressure over the range 0-50 psi and the crossflow velocity $0-3 \mathrm{~m} \mathrm{~s}^{-1}$ whilst keeping the feed at a temperature of $30 \pm 2^{\circ} \mathrm{C}$.

The purpose built microfilter was constructed from plastic and stainless steel (as was the rest of the flow circuit and ancillaries) and consisted of a supported $24 \mathrm{~cm}^{2}$ membrane positioned to form one side of a rectangular flow section. During an experiment the suspension flowed through this 
volume and tangential to the membrane. The filtrate produced was collected in a compartment behind the membrane and returned to the feed tank via a flowmeter.

Experiments have been performed using aqueous suspensions of calcite (calcium carbonate) and anatase (titanium dioxide). Calcite was chosen as a system where surface effects are relatively small whereas anatase is typical of a system where the surface chemistry and environmental conditions could have a significant effect. Nuclepore polycarbonate membranes where used as the filtering medium.

Prior to the start of a filtration test the process suspension, made to a known concentration from either a dry powder and double distilled water or from a diluted slurry, was stirred in the feed tank for several minutes to produce a homogeneous mixture. The suspension $\mathrm{pH}$ was then altered if necessary using $\mathrm{NaOH}$ or $\mathrm{HCl}$. No other dispersants or flocculants were added. The test was then performed at the desired filtration settings with data recorded and permanently stored by the computer on floppy disk. Each test was run for a maximum of two hours or until the membrane fouled to such an extent that the flow rate could not be recorded satisfactorily.

\section{Membrane Characterisation}

In support of the filter fouling assessment experiments the suspensions and membranes were characterised through a series of independent tests. The properties measured are summarised in Table 1.

The pore size distributions of the Nuclepore polycarbonate membranes were measured with a Coulter porometer. Unsoiled samples of the membranes used in the filtration experiments were tested in accordance with ASTM $1294-89^{1}$ and the results are shown in Figure 2 . They show that the membranes exhibit narrow pore size distributions around mean values which are close to the manufacturer's quoted ratings. The pore size distribution was found to widen for the membranes with larger pore size ratings, a phenomenon associated with membranes produced by nuclear track etching techniques. The membrane topography was also examined using scanning electron microscopy, which confirmed the predominantly cylindrical nature and random dispersity of the pores over the membrane. The pores were of constant shape through the membrane, and the membranes were homogeneous.

The permeability and 'clean water flux' of the membranes were measured in a pressure driven permeameter. For each sample the permeation rates corresponding to a series of applied pressure differences were determined, and Darcy's Law used to give its permeability. These tests were performed with double distilled water at $20^{\circ} \mathrm{C}$. Table 2 gives the membrane characterisation data.

The contact angles between various suspensions and the membranes were also measured. The technique developed utilised a borescope, a high speed, high sensitivity camera and a thermal image printer. A small sample of membrane was positioned in front of the high magnification borescope such that only its 'edge' was visible. A drop of the suspension was then placed onto the membrane surface using a micro-syringe, and a picture recorded using the attached printer. The contact angle between the droplet and the membrane was then measured on the first picture taken (refinement of the technique would enable the rate of penetration of fluid into the membrane to be evaluated, as the contact angle and the size of the droplet could be readily measured as a function of the fluid-membrane contact time). The experimental difficulties involved led to some scatter in the results, particularly at higher $\mathrm{pH}$ 's where membrane wettability appeared to improve. The results, some shown on Figure 3, suggest a small variation of contact angle for the range of suspensions examined, and it is probably reasonable to assume that wettability differences between different suspensions are likely to be a secondary effect in the filtration experiments.

\section{Particle Characterisation}

Cite paper as: Wakeman R.J. and Tarleton E.S., 1991, Colloidal fouling of microfiltration membranes during the treatment of aqueous feed streams, Desalination, 83, 35-52. Also presented at $12^{\text {th }}$ International Symposium Desalination and Water Re-use, 1991, pp.35-52, IChemE, Valetta, Malta. 
The particle size distributions of the test suspensions were evaluated using Malvern Auto- and Master- Sizer instruments. The calcite powder was an analar grade supplied by $\mathrm{BDH}$, and the anatase was obtained from Tioxide PLC in an uncoated form. No further cleaning or washing of the powders was performed prior to either the size analyses or the microfiltration experiments. The measured particle size distributions for the powders dispersed in double distilled water are shown in Figure 4. The smallest mean size was exhibited by anatase with most of the particulates in the region of $0.5 \mu \mathrm{m}$. In contrast the unground calcite suspension had a mean size of approximately $27.5 \mu \mathrm{m}$ and a wide distribution. When the calcite was wet ground for one day in a ball mill the mean size was reduced to $2.7 \mu \mathrm{m}$.

The particle shapes the powders were examined with a scanning electron microscope using standard techniques. Calcite, in both its ground and unground forms, exhibited a rhomboidal shape and anatase resembled its characteristic modular form (albeit shrouded by the extent of aggregation of the particles at some $\mathrm{pH}$ 's).

\section{Suspension Characterisation}

The effect of $\mathrm{pH}$ (and ionic strength) on particle surface charge was determined using a Malvern Zetasizer. Calcite has a relatively low surface charge with the points of zero and maximum negative zeta potential $(-24 \mathrm{mV})$ at the $\mathrm{pH}$ 's 8.9 and 10.6 respectively. Anatase is typical of a high surface charge material and the $\mathrm{pH}$ 's 3.9 and 9.1 represent zeta potentials of $0 \mathrm{mV}$ and $-47 \mathrm{mV}$ respectively.

A Carrimed controlled stress rheometer was used to investigate the suspension rheology. The behaviour of the suspensions were found to be Newtonian, as might be expected from the relatively low solids concentrations being used.

\section{EXPERIMENTAL RESULTS}

The matrix of properties shown in Table 3 has been investigated for both calcite and anatase suspensions. The parameters shown were found to affect crossflow microfiltration to an extent dependent on their relative magnitudes, although all the tests performed showed the same general overall characteristics. When the filtration test commenced a sharp fall in filtration rate from the clean water flux was observed. The rapid fouling of the membrane during this period can be attributed to the accumulation of particulate matter at or near the filtering surface (particle polarisation). After this initial period the rate of flux decline progressively lessened until after some time an equilibrium filtration rate was observed in most experiments. When this state is reached it would seem that the particles forming the fouling layer are in a state of 'dynamic equilibrium' whereby particles are leaving and joining the layer at the same rate $^{2}$.

\section{Effects of Filtration Pressure}

Figure 5 illustrates the typical effects of raising the filtration pressure whilst keeping the other experimental conditions constant. In all cases it was found that an increased filtration pressure resulted in an improved filtration rate. This could have been expected from Darcy's law which indicates that flux is directly proportional to the applied pressure gradient, unless the increase of resistance of any deposit at the membrane surface was proportional to (pressure) ${ }^{n}$ with $n>1$. This was not found to be so, and other work on the resistance of deposits formed in filtration shows that $n<1^{3,4}$.

When the mean size of particle in the suspension was reduced from $27 \mu \mathrm{m}$ to $2.7 \mu \mathrm{m}$ by wet grinding prior to filtration the improvements in flux obtained by raising the filtration pressure were reduced, and there was also a tendency for an equilibrium flux to be established more rapidly at 
lower filtration pressures. It is well established in ultrafiltration ${ }^{5,6}$, and there are reports of similar effects in microfiltration ${ }^{7}$, that an increased filtration pressure will not always produce an improved filtration performance. Molecular adsorption effects at the surface of membranes in ultrafiltration can lead to situations where potential improvements gained by raising the pressure are more than offset by an increase in the flow resistance of the fouling layer. Results from the filtration of an anatase suspension (with an average particle size of $0.5 \mu \mathrm{m}$ ) at different pressures show that the permeate fluxes recorded after two hours filtration are almost the same. Although this indicates that fouling had occurred to a similar extent irrespective of the pressure difference, the fouling is due to two apparently independent mechanisms which occur simultaneously. The first accounts for the initial rapid decline in permeate rate and is irreversible for all practical purposes, and is due to the capture of the finer particles from the suspension and their penetration into the pores of the membrane. This is a stochastic process, dependent on localised hydrodynamic conditions close to the pore entrances. The second mechanism is largely reversible and causes a particulate layer to form above the membrane surface; the formation of this layer is due to shear induced diffusion of particles towards the surface to form a concentrated layer which may be either mobile or stationary, dependent on flow conditions in the flow volume above the membrane surface. There is no evidence that either of the mechanisms responsible for particulate fouling is due to adsorption.

\section{Effects of Crossflow Velocity}

When tests were performed at various crossflow velocities a rather curious result was produced. Figures 6 and 7 show the data obtained for ground and unground calcite suspensions respectively, under otherwise identical filtration conditions. With the ground suspension the expected result was obtained, that is an increased crossflow velocity produced an improved filtration flux. Here the additional shearing forces generated at the higher velocities caused less particulates to accumulate at the membrane and thus facilitated reduced fouling. However, when the feed stream contained a greater proportion of larger, unground particles the filtration rate was seen to fall with increasing crossflow velocity. This unforeseen, although not unknown, phenomenon might at present be best explained in terms of particle classification near the filtering surface. It is known that the fouling layer which appears during crossflow microfiltration is invariably formed from the finer particle species present in the feed suspension ${ }^{8,9}$. The axial velocity gradient which is generated across the flow channel causes the larger particles in suspension to migrate away from the septum at a faster rate than the smaller one ${ }^{90}$, hence the layer responsible for membrane fouling could have a resistance considerably higher than that which might be expected from a simplistic approach.

The results obtained with the unground calcite suspensions may then possibly be explained by the 'tubular pinch effect'. As the crossflow velocity was increased more of the larger particles, which were potential foulants, remained in suspension. Thus, the fouling layer deposited at or near the membrane surface was composed of progressively finer particle species which formed higher resistance 'cakes' and caused lower filtration rates. Unfortunately the lack of formation of a true filter cake and the resultant difficulty of taking a representative sample prevented the measurement of the size distribution of the fouling deposit.

Currently, the effects of increasing the crossflow velocity on filtration flux seem wholly attributable to the size and size distribution of the dispersed phase in suspension. The results suggest that for a given calcite suspension there will exist a critical size distribution where the crossflow velocity should have little or no effect on the flux decline curve achieved. The experiments using smaller particle size suspensions also highlighted some other interesting results. Figure 6 shows that an equilibrium flux is established more rapidly at lower crossflow velocities, and this effect was found to be more pronounced with the finer anatase suspensions. When the crossflow was raised to 2.3 $\mathrm{m} \mathrm{s}^{-1}$ the filtration flux was seen to progressively decline over the period of the experiment. Here, the shearing action of the crossflowing stream is apparently insufficient to overcome the forces which cause particles to accumulate at the membrane and form the fouling layer. In relation to the 
mechanisms described in the previous section it is likely that the fouling layer is in a predominantly mobile state at the higher crossflow velocities, and is approaching stagnation at the lower crossflow velocities.

\section{Effects of Suspension Concentration}

Whilst all of the data collected showed similar effects of suspension concentration on permeate flux decline a number of points are worth noting. The general effect of increasing the solids concentration of the feed suspension was to lower the filtrate flux. However, in several cases similar fluxes were recorded at longer filtration times for different suspension concentrations. This effect was primarily a consequence of the more rapid establishment of an equilibrium flux at higher feed concentrations and exaggerated at smaller particle sizes. When the feed stream is more concentrated there is a preference for filtration to occur with particles bridging membrane pores rather than plugging them. If a more dilute suspension is filtered, however, there is a tendency for pore plugging to occur to a more significant extent. During the initial stages of filtration the results suggest that for different feed concentrations the fouling mechanisms are significantly dissimilar with pore blocking and bridging occurring to various extents. However, after an initial period the fouling mechanisms would seem to change gradually and become more similar. This implies that one fouling mechanism is being superseded by another during the filtration, or that if only one fouling layer were to exist its structure and composition are changing throughout the filtration.

\section{Effects of Suspension pH}

The effects of $\mathrm{pH}$ on the filtration were determined at $\mathrm{pH}$ 's which represented the point of zero charge and peak surface charge. With calcite only exhibiting a relatively low zeta potential in combination with a 'large' particle size it is not surprising that virtually no change was detected in the flux decline curves; in this case surface effects play only a minor role. Anatase, which can exhibit a high zeta potential and 'small' particle size in aqueous suspension, was found to be much more sensitive to changes in $\mathrm{pH}$ and surface properties. At higher concentrations in particular, and where surface forces are greater up to a five fold difference in filtrate flux could be observed between high and low $\mathrm{pH}$ experiments.

It is well documented that 'stable' high zeta potential suspensions are invariably more difficult to filter than low zeta potential systems ${ }^{11,12}$. In the state of high surface charge particles in suspension are well dispersed by mutually repulsive electrostatic forces and form high resistance deposits during filtration. (These deposits correspond to the first of the two postulated mechanisms, leading to irreversible fouling of the pores). However, near the point of zero surface charge (isoelectric point) particles in suspension tend to agglomerate, due mainly to attractive Van der Waals forces, and the fouling layer formed in membrane filtration is of a lower resistance. (In this case fewer particles are deposited by the first mechanism (stochastic penetration of the pores), and the second mechanism (formation of a fouling layer) plays a greater role). The results obtained suggest that whenever possible membrane filtration should be performed with the particles in the feed suspension at or near the point of zero surface charge. Such an effect can be produced by altering the $\mathrm{pH}$ and/or ionic strength of the solution environment surrounding the particles.

\section{Effects of Particle Size}

Figures 8 and 9 show typical effects of changing the mean particle size of a calcite suspension on flux decline at two different crossflow velocities. With a smaller particle size there was a tendency for the filtrate flux to be reduced more rapidly. However, the equilibrium fluxes recorded for 'large' and 'small' particle systems were often similar in magnitude. In a previous section the crossflow velocity was shown to affect ground and unground calcite suspensions in different ways. For a large particle system a raised crossflow velocity caused the filtrate flux to fall, whilst in a smaller particle system the opposite effect (of improving the filtration rate) was found. Thus, a higher 
crossflow velocity will tend to move the fluxes measured for different particle size feeds closer together and may result in the flux recorded for the smaller particle size system being above that measured for the larger.

It seems likely that the fouling layers formed during the filtration of different particle size systems will be of a different structure and composition. In conventional deadend filtration, where the bulk suspension flow is normal to the filtering medium, smaller particle systems usually form cakes with a higher resistance to filtration than large particle systems. In crossflow microfiltration, however, the situation is complicated by the particle classification phenomenon (tubular pinch effect). Such an effect makes identifying the particles responsible for the formation and structure of the fouling layer more difficult to quantify.

\section{Effects of Membrane Pore Size}

Membrane pore size was found to affect filtration performance to an extent dependent on a number of factors. In experiments using unground and ground calcite suspensions the effects of pore size were minimal when the pore size was smaller than the mean particle size (it must be noted that within the particle size distribution there were, in all cases, particles whose sizes were finer than the pore sizes and so effects of pore penetration could not be eliminated from the experiments altogether). At the particular experimental conditions the fluxes recorded are very similar with only the initial stages of filtration showing any discernible difference in flux performance. The result is perhaps surprising when one considers the relative permeabilites of the membranes used in the tests (see Table 2). The characterisation experiments showed that there are approximately two orders of magnitude difference in the permeabilities of $10 \mu \mathrm{m}$ and $0.2 \mu \mathrm{m}$ Nuclepore polycarbonate membranes with intermediate pore size ratings somewhere in between. Thus, it would be reasonable to assume that the use of more permeable membranes would produce improved permeation rates while allowing macromolecular and maybe some fines pass through the membrane with the filtrate. The fact that little difference in permeation rates (or permeate clarity) was observed with calcite suspensions and various pore size membranes suggests that it was the fouling layer formed during filtration which played the most significant role in determining flux performance.

When anatase or ground calcite suspensions were filtered using different pore size membranes a further effect was observed. Figure 10 shows a sample of the results. Whilst in a few cases virtually no difference in flux performance could be detected, the majority of tests indicated that increasing the membrane pore size caused a reduced filtration performance both in terms of flux levels and quality of filtrate. The filtrate quality usually improved with filtration time as the deposit on the membrane gradually formed. In the case of these finer suspensions it seems that the extent of membrane fouling was more dependent on penetration of particles into the membrane, rather than merely on the formation of a surface fouling layer.

The fouling layer or so called 'secondary' or 'dynamic' membrane formed in membrane filtration has previously been recognised as an important factor in determining flux decline ${ }^{13,14}$. It has been proposed that three distinct classes of dynamic membrane can be identified, depending on the ratio of feed particle size to membrane pore size. The extent to which any of these formed in the experiments reported in this paper is presently unclear. However, it seems likely that the finer particle filtrations involved a degree of internal pore blocking by particulates whilst in the coarser particle experiments there may have more pore bridging and plugging phenomena occurring. These terms say nothing about the static or dynamic state of any fouling layer and, although it is inadequate to take terminology directly from dead-end filtration technology, it can be helpful to draw analogies between dead-end and crossflow filtrations.

\section{CONCLUDING REMARKS}

Cite paper as: Wakeman R.J. and Tarleton E.S., 1991, Colloidal fouling of microfiltration membranes during the treatment of aqueous feed streams, Desalination, 83, 35-52. Also presented at $12^{\text {th }}$ International Symposium Desalination and Water Re-use, 1991, pp.35-52, IChemE, Valetta, Malta. 
During the initial stages of microfiltration membrane fouling occurs very rapidly; this part of the flux decline process is due to fines in the feed stream being captured and embedded in the membrane pores, and is effectively irreversible. The second stage of fouling is due to the formation of layers carrying higher solids concentrations above the membrane surface; these layers can be either mobile or stagnant, and they result in a fouling which is reversible. Direct evidence of the existence of these layers is being collected in a related research project, and will be the subject of a future report.

Raising the filtration pressure results in an increased permeate flux, but the increase can be small and not in proportion to the increase in filtration pressure. This is particularly so for finer particles. At lower pressures an equilibrium flux is established more rapidly.

Increasing the crossflow velocity can either increase or decrease the filtrate flux. The effect observed is attributable to the size and size distribution of the dispersed phase, and the behaviour of that phase at the membrane surface. There is evidence that a 'critical' particle size will exist for any set of operating conditions, such that crossflow velocity will have no effect on the permeate flux decline curve.

Permeate fluxes are generally lower with feeds containing finer particle sizes, although equilibrium fluxes are established more rapidly. Flux levels are also apparently lower with feeds containing smaller particle sizes, but if the size distribution of the coarser particles includes any fines the equilibrium flux reached may be same as that obtained with a feed containing a smaller mean size. However, the rate of approach to equilibrium is more rapid when no coarse particles exist.

Changing the $\mathrm{pH}$, and hence zeta potential, of the feed affects filtration to an extent dependent on the nature of the particle present and their surrounding fluid environment. As a general rule both permeate quality and rate are enhanced at lower zeta potentials. The influence of membrane pore size is evident at both short and long filtration periods; the ratio of pore to particle sizes is an obvious factor to be considered here. When the pore size is smaller than the particle size neither the equilibrium flux nor the rate of approach to it differ appreciably as the pore size is changed. But when the pore size is larger than the particle size the equilibrium flux is reduced as the pore size is increased (and the rate of approach to it is simultaneously increased).

The work reported in this paper is part of an integrated series of projects being carried out on membrane filtration, aimed at providing fundamental understanding and technical solutions to the fouling problem. As such, this experimental programme is not yet complete but the results presented here are considered to be correct in the general context. They will ultimately provide a comprehensive picture of the causes of particulate fouling and, together with appropriate modelling of the process, it is expected that a new approach to the design and sizing of crossflow microfilters may result. Few of the parameters considered in this paper a independent of each other in any 'real' filtration problem, and attempts are in progress to develop a global model which will take account of all the basic parameters together with their interactions. The model is partly developed and takes full account of the differing mechanisms which occur at and in the membrane.

\section{ACKNOWLEDGEMENTS}

The authors wish to acknowledge the grant awarded and helpful technical discussions provided by the BP Research Centre, Sunbury on Thames.

\section{REFERENCES}

1. ASTM E 1294, 1989. 
2. Romero C.A. and Davis R.H., J. Mem. Sci., 39, 157, 1988.

3. Shirato M., Murase T., Iritani E., Tiller F.M. and Alciatore A.F., in Filtration, $2^{\text {nd }}$ Edn., M.J. Matteson and C. Orr (Eds.), Marcel Dekker, New York, 1987.

4. Wakeman R.J., Sabri M.N. and Tarleton E.S., 1991, Powder Technol., 65, 283-292.

5. Fane A.G., in Progress in Filtration and Separation, Vol.4, R.J. Wakeman (Ed.), Elsevier, Amsterdam, 1986.

6. Blatt W.F., Dravid A., Michaels A.S. and Nelson L., in Membrane Science and Technology, J.E. Flinn (Ed.), Plenum Press, New York, 1970.

7. Fischer E. and Raasch J., Proc. $4^{\text {th }}$ World Filtration Congress, Ostend, Belgium, 1986.

8. Murkes J. and Carlsson C.G., Crossflow Filtration, Wiley, Chichester, 1988.

9. Milisic V. and Ben Aim R., Filt. and Sep., 23(1), 28, 1986.

10. Altena F.W. and Belfort G., Chem. Eng. Sci., 39, 343, 1984.

11. Bratby J., Coagulation and Flocculation, Uplands Press, London, 1980.

12. Wakeman R.J., Thuraisingham S.T. and Tarleton E.S., Filt. and Sep., 26(4), 277, 1989.

13. Osterman A.E., Proc. $4^{\text {th }}$ World Filtration Congress, Ostend, Belgium, 1986.

14. Holdich R.G. and Boston R.G., Proc. Filtech Conf., Karlsruhe, 1989. 


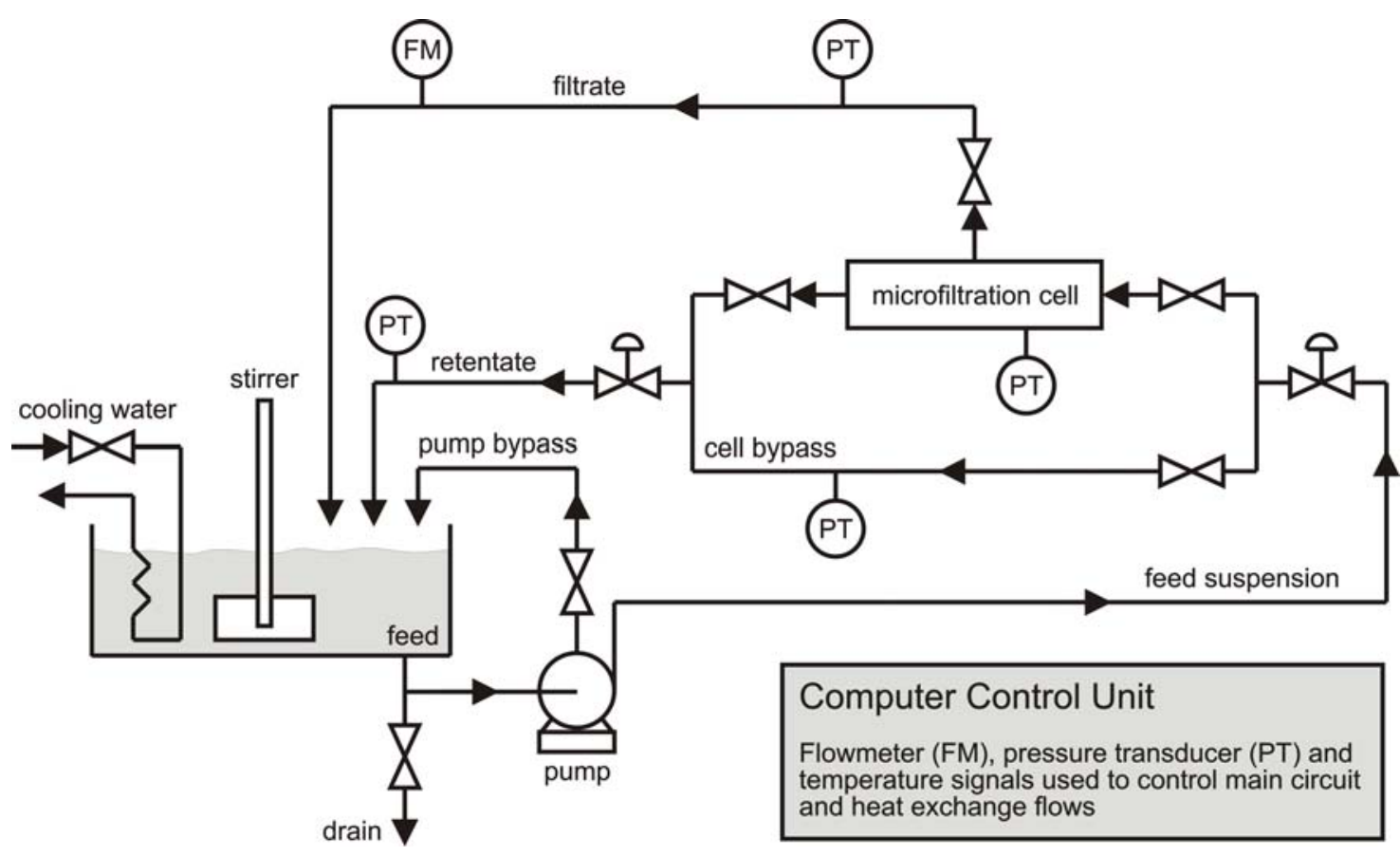

Figure 1: Schematic of the microfilter fouling assessment unit.

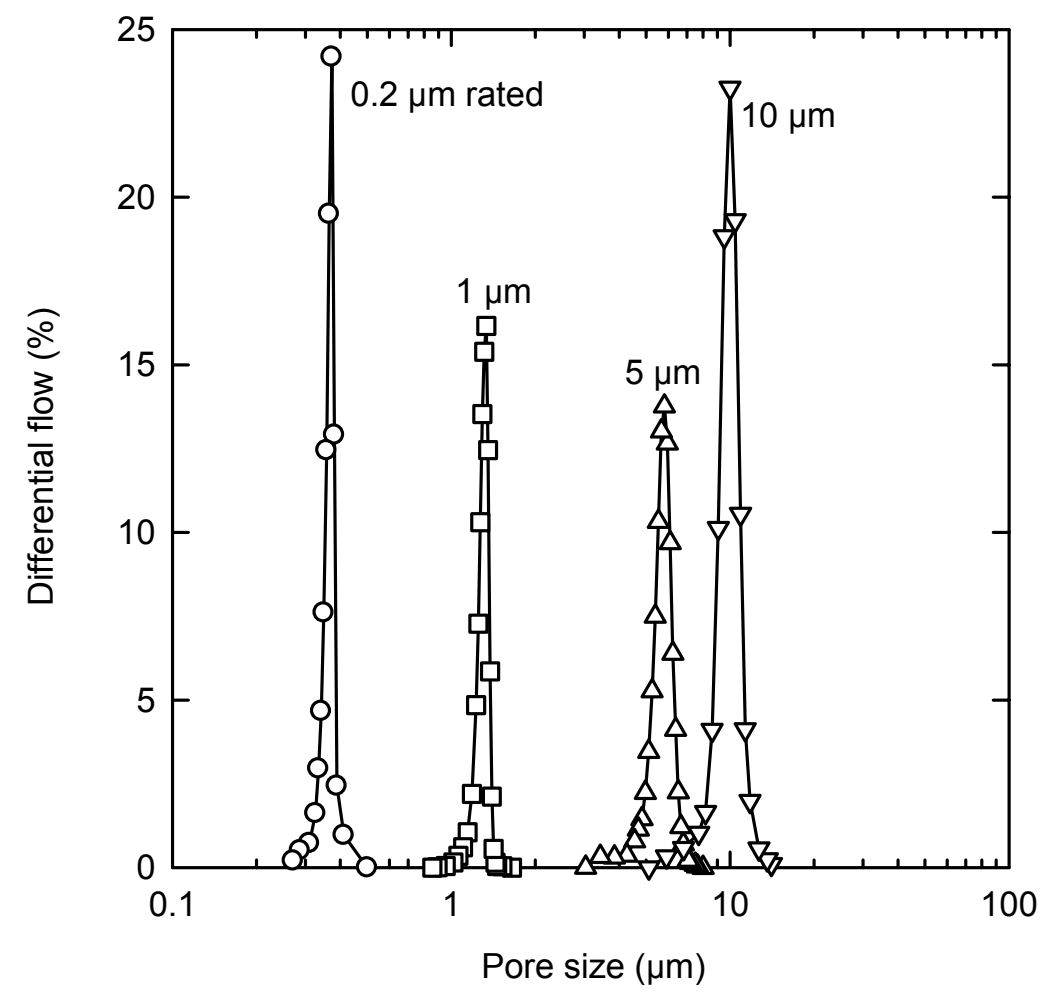

Figure 2: Pore size distributions of the Nuclepore polycarbonate membranes. 


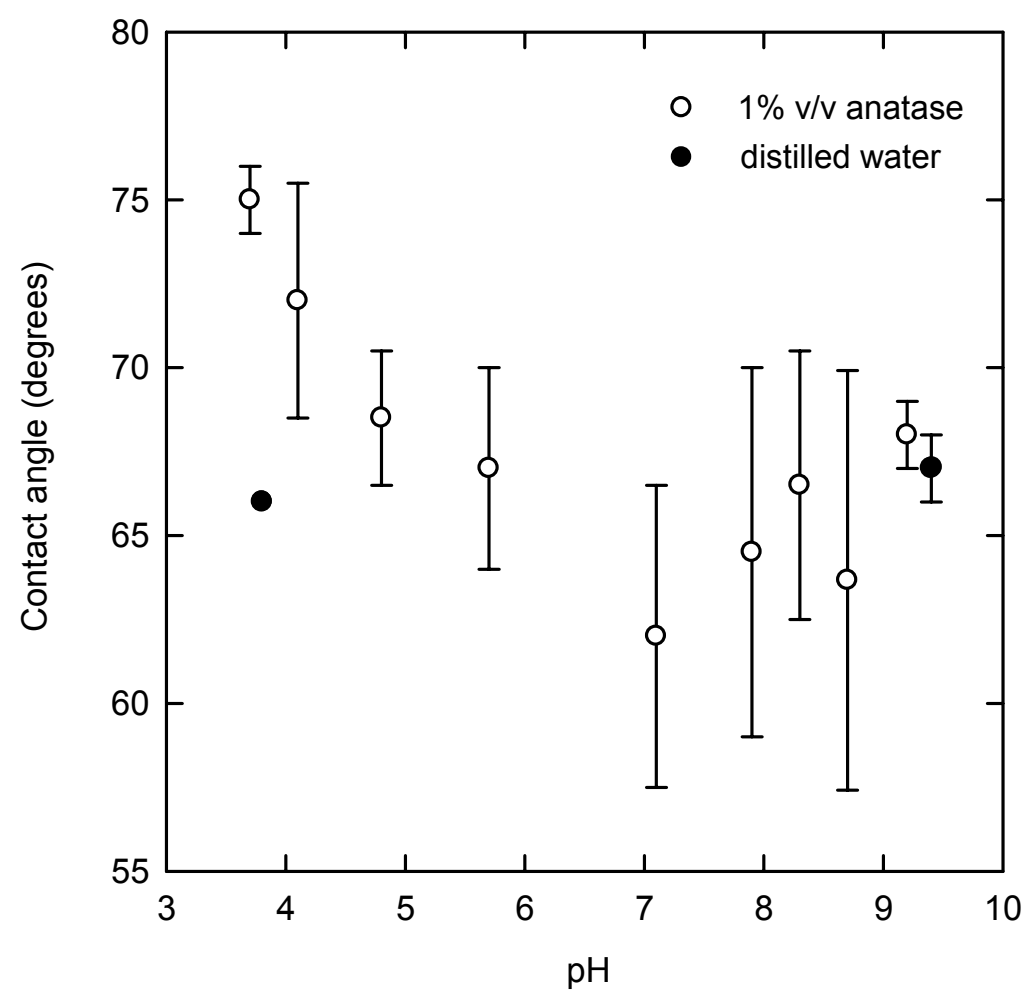

Figure 3: Contact angle vs. $\mathrm{pH}$ for $1 \% \mathrm{v} / \mathrm{v}$ anatase suspensions on Nuclepore membranes.

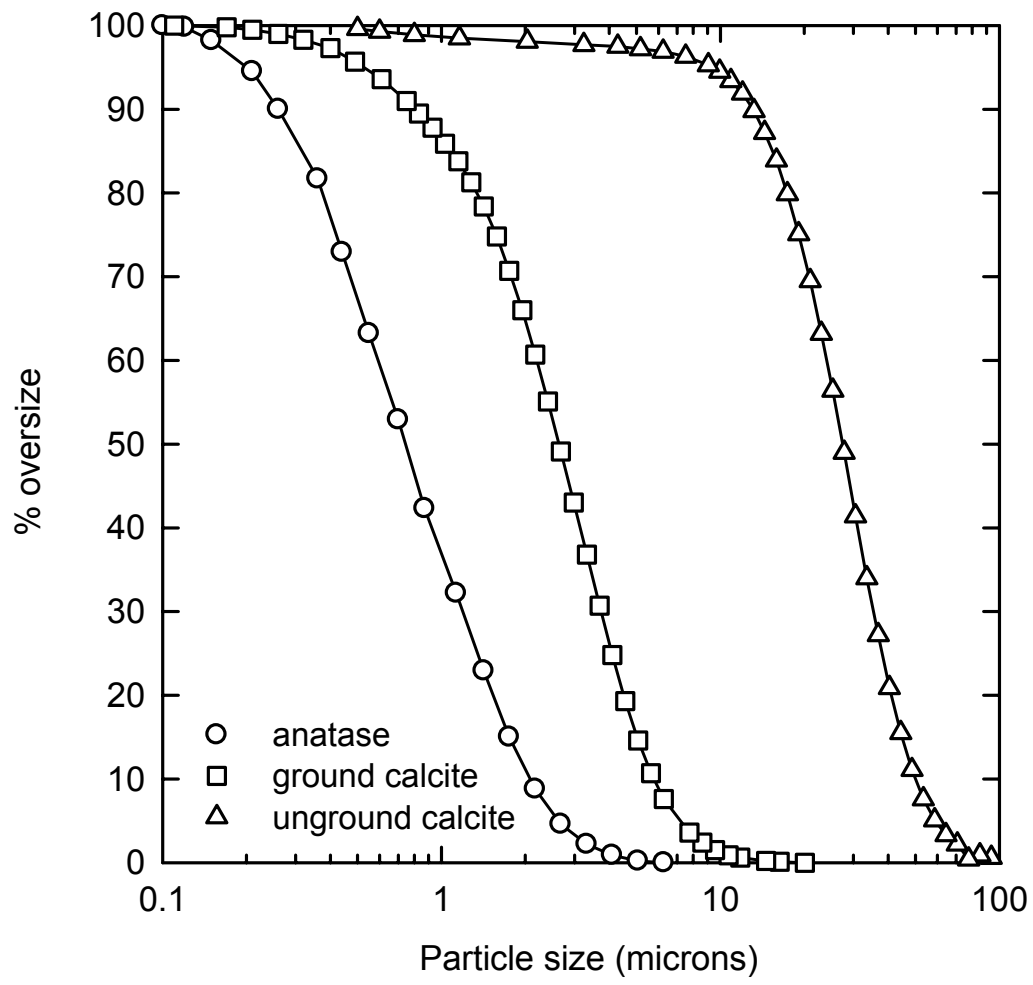

Figure 4: Size distributions of the particles. 


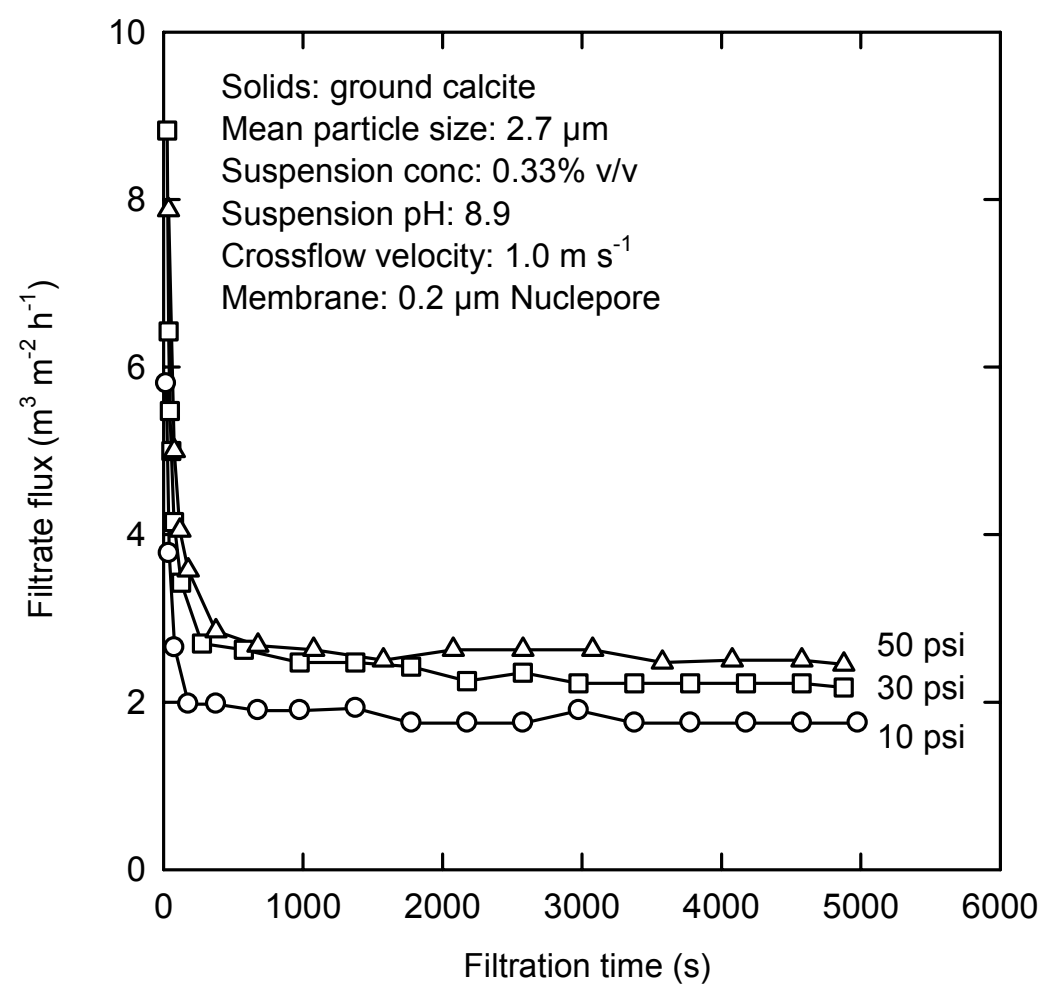

Figure 5: Effect of pressure on flux decline for fine calcite suspensions.

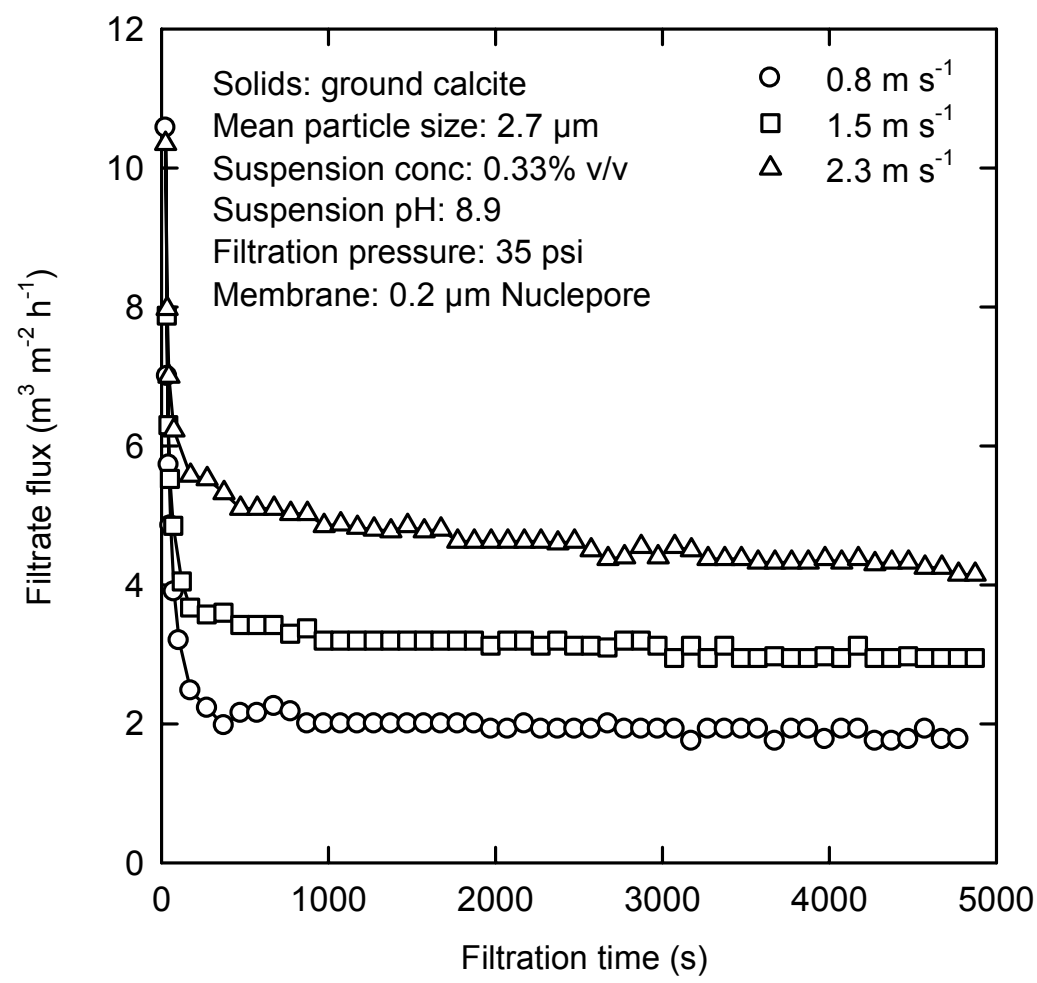

Figure 6: Effect of crossflow velocity on flux decline for ground calcite suspensions. 


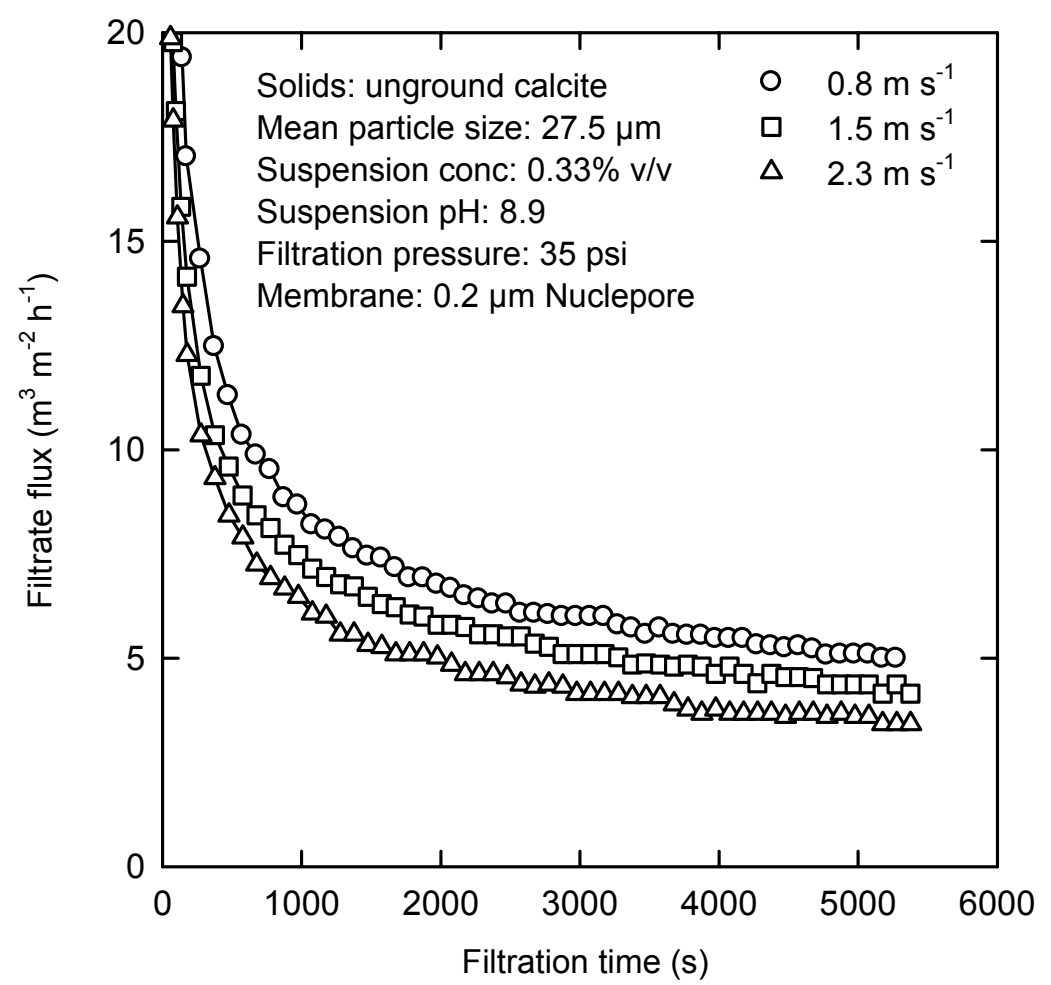

Figure 7: Effect of crossflow velocity on flux decline for coarse calcite suspensions.

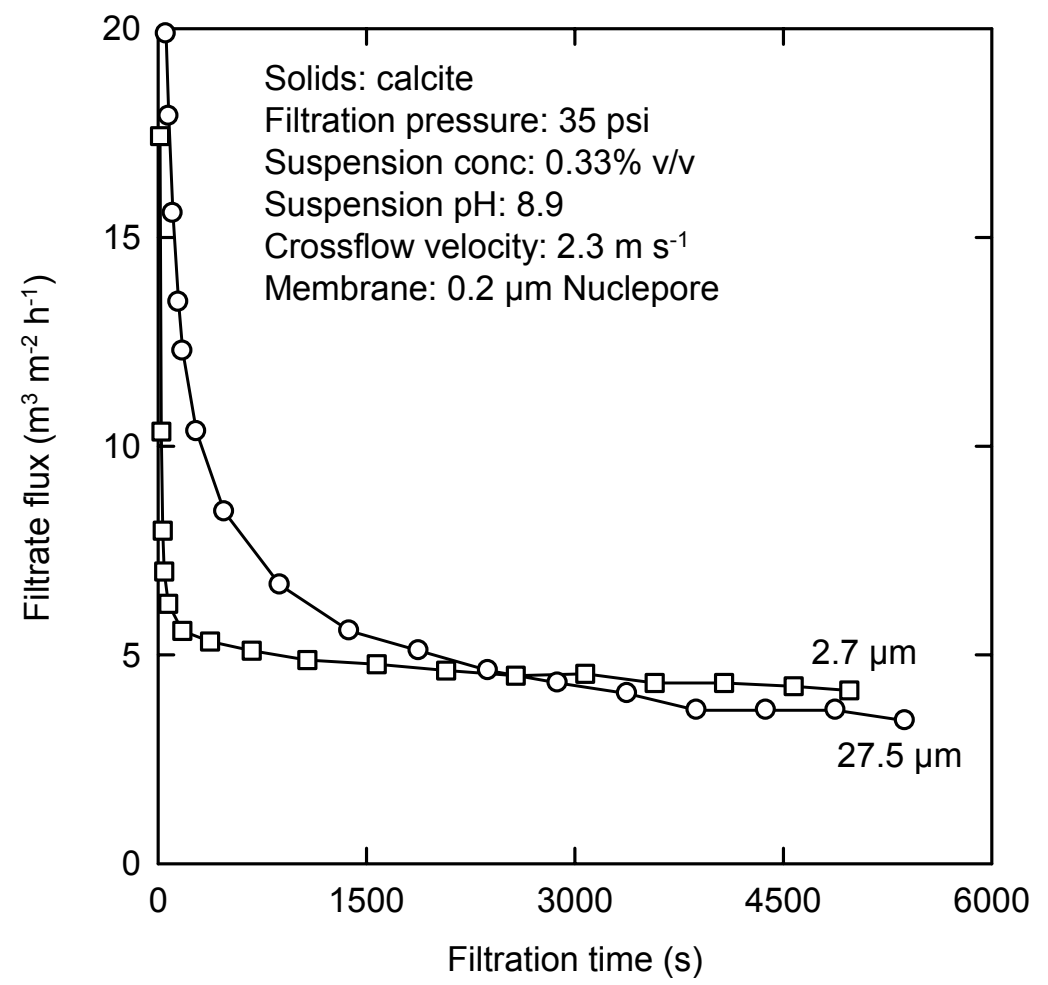

Figure 8: Effect of particle size on flux decline for calcite suspensions at higher crossflow velocities. 


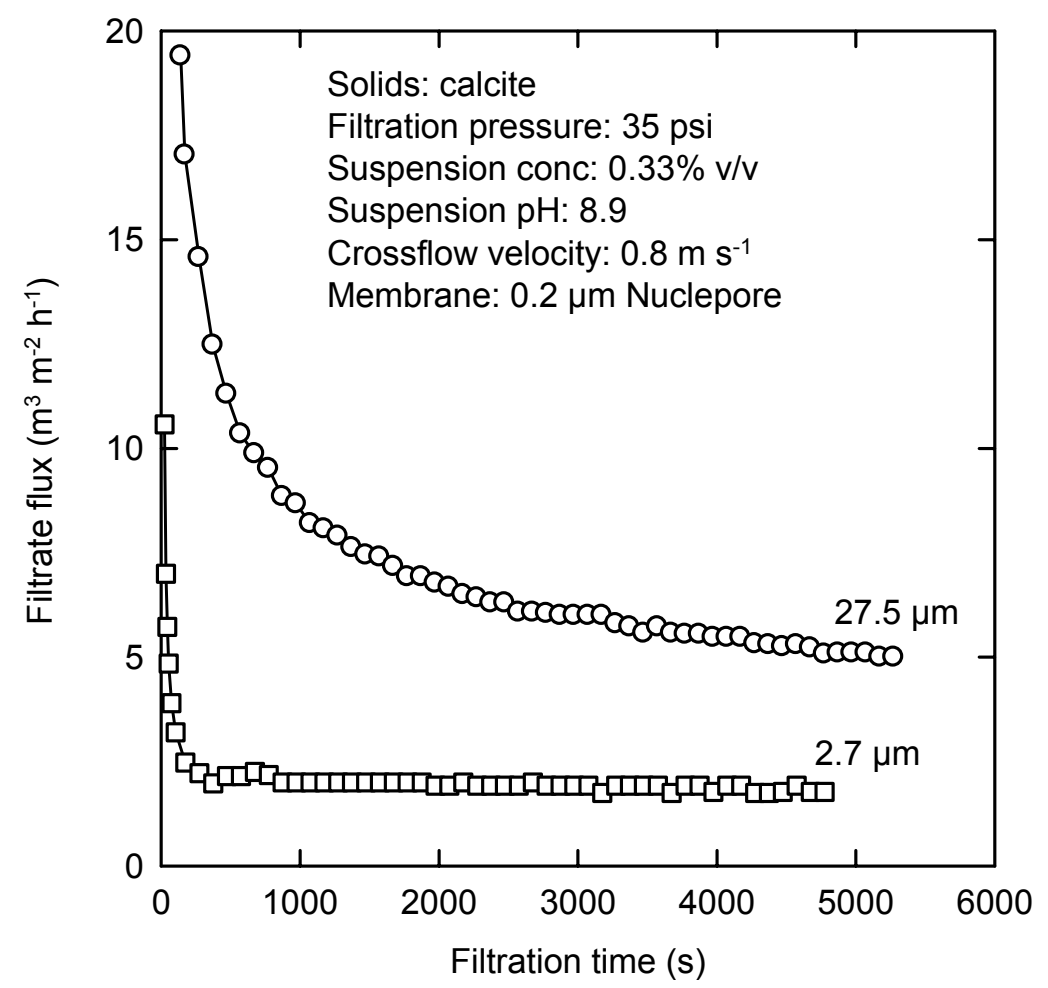

Figure 9: Effect of particle size on flux decline for calcite suspensions at lower crossflow velocities.

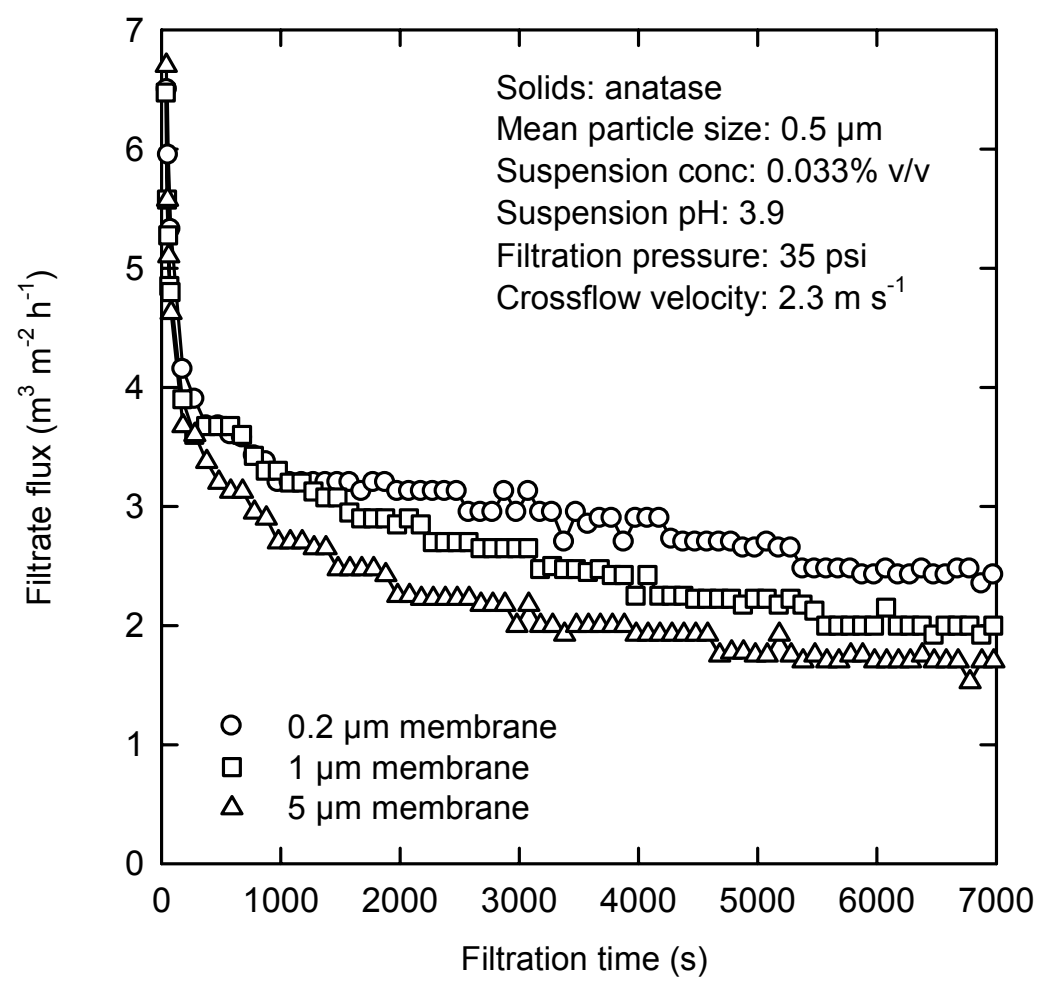

Figure 10: Effect of membrane pore size on flux decline for anatase suspensions. 


\begin{tabular}{|l|l|}
\hline Particle/process stream & Membrane \\
\hline Size/size distribution & Pore size/size distribution \\
Particle shape & Asymmetry \\
pH - - -potential relationship & Pore shape \\
Rheology & Wettability \\
& Permeability \\
\hline
\end{tabular}

Table 1: Parameters evaluated in the characterisation experiments.

\begin{tabular}{|c|c|c|c|}
\hline $\begin{array}{c}\text { Membrane } \\
\text { rating }(\mu \mathrm{m})\end{array}$ & $\begin{array}{c}\text { Thickness } \\
(\mu \mathrm{m})\end{array}$ & $\begin{array}{c}\text { Pore density } \\
\left(\text { pores } / \mathrm{cm}^{2}\right)\end{array}$ & $\begin{array}{c}\text { Permeability } \\
\left(\mathrm{m}^{2}\right)\end{array}$ \\
\hline 10 & 10 & $1 \times 10^{5}$ & $1.1 \times 10^{-14}$ \\
5 & 10 & $4 \times 10^{5}$ & $9.4 \times 10^{-15}$ \\
1 & 11 & $2 \times 10^{7}$ & $1.5 \times 10^{-15}$ \\
0.2 & 10 & $3 \times 10^{8}$ & $2.7 \times 10^{-16}$ \\
\hline
\end{tabular}

Table 2: Characteristics of the membranes used in the experiments.

\begin{tabular}{|l|l|l|}
\hline Feed stream & Membrane & Process parameters \\
\hline $\begin{array}{l}\text { Particle size } \\
\text { pH (surface charge) }\end{array}$ & Pore size & $\begin{array}{l}\text { Solids concentration } \\
\text { Crossflow velocity } \\
\text { Filtration pressure }\end{array}$ \\
\hline
\end{tabular}

Table 3: Matrix of properties examined in the filtration experiments. 